\title{
Inveja na percepção dos professores universitários de instituições públicas Paraibanas
}

Este estudo tem como objetivo identificar a percepção que os professores universitários de instituições públicas paraibanas detêm sobre a inveja em seus locais de trabalho, por meio da técnica de associação livre de palavras (TALP). As discussões trataram sobre a inveja e suas consequências destrutivas que levam ao sofrimento emocional por meio de comparações ascendentes entre indivíduos. Trata-se de uma pesquisa qualitativa realizada com uma amostra de 69 professores universitários de instituição de ensino superior públicas da Paraíba. Os dados foram coletados por meio de uma survey online. As respostas foram processadas no software IRAMUTEQ versão 7 e analisados a partir da técnica de classificação hierárquica descendente, similitude e nuvem de palavras. Foram observadas 208 ocorrências de palavras, sendo 110 formas distintas. Destas, foram encontradas 79 (71,82\%) palavras equiparadas por meio hierárquico descendente, que resultaram em 2 categorias: inveja numa percepção emocional e a outra dolorosa. Os resultados indicam uma certa variação na percepção conceitual da palavra inveja, uma vez que pode assumir condutas distintas, como: indiferença, raiva, cobiça, ironia, calúnia, deboche, ódio, desrespeito e, tantos outros. Por fim, concluise que a inveja pode ser compreendida como uma emoção ascendente, por enfatizar elementos afetivos negativos desagradáveis, muitas vezes dolorosos caracterizados por sentimentos de inferioridade, hostilidade e ressentimento produzidos pela consciência de outro.

Palavras-chave: Inveja; Professores; Intuições Públicas.

\section{Envy on the perception of university teachers of Paraiba public institutions}

\begin{abstract}
This study aims to identify the perception that university professors from public institutions in Paraíba hold about envy in their workplaces through the technique of free word association (TALP). The discussions dealt with envy and its destructive consequences that lead to emotional distress through upward comparisons between individuals. This is a qualitative research conducted with a sample of 69 university professors from a public higher education institution in Paraiba. Data were collected through an online survey. The answers were processed using IRAMUTEQ version 7 software and analyzed using the descending hierarchical classification technique, similarity and word cloud. A total of 208 word occurrences were observed, with 110 distinct forms. Of these, 79 (71.82\%) words were found matched by descending hierarchy, resulting in 2 categories: envy in an emotional perception and the other painful. The results indicate a certain variation in the conceptual perception of the word envy, since it can assume different behaviors, such as: indifference, anger, greed, irony, slander, mockery, hatred, disrespect, and many others. Finally, it is concluded that envy can be understood as an upward emotion by emphasizing unpleasant, often painful negative affective elements characterized by feelings of inferiority, hostility and resentment produced by the consciousness of another.
\end{abstract}

Keywords: Envy; Teachers; Public intuitions.

Topic: Recursos Humanos

Reviewed anonymously in the process of blind peer
Received: $15 / 10 / 2019$

Approved: 21/12/2019
Mary Dayane Souza Silva (iD)

Universidade Federal do Pernambuco, Brasil http://lattes.cnpq.br/9393194690113819

m.dayane.silva@gmail.com

Antonio Roazzi (io

Universidade Federal do Pernambuco, Brasil http://lattes.cnpq.br/6108730498633062

http://orcid.org/0000-0001-6411-2763 roazzi@gmail.com

Francisca Rozângela Lopes de Sousa (iD) Universidade Estadual da Paraíba, Brasil http://lattes.cnpq.br/7564029475757969 http://orcid.org/0000-0003-2770-7666 rhozeadm@hotmail.com

\author{
Adriana Sousa Silva (iD) \\ Universidade Federal de Campina Grande, Brasil \\ http://lattes.cnpq.br/1596429840157832 \\ http://orcid.org/0000-0002-1623-8887 \\ adriana.s.sousa@gmail.com \\ Geymeesson Brito da Silva (id \\ Universidade Estadual da Paraíba, Brasil \\ http://lattes.cnpq.br/7331740582805322 \\ http://orcid.org/0000-0002-1420-6371 \\ geimerson18@hotmail.com
}

\section{Referencing this:}

SILVA, M. D. S.; ROAZZI, A.; SOUSA, F. R. L.; SILVA, A. S.; SILVA, G. B.. Inveja na percepção dos professores universitários de instituições públicas Paraibanas. Revista Brasileira de Administração Científica, v.10, n.4, p.31-49, 2019. DOI: http://doi.org/10.6008/CBPC2179$684 \times .2019 .004 .0003$ 


\section{INTRODUÇÃO}

A literatura sobre inveja em seus diferentes aspectos, experimentou significativo crescimento nas últimas década. Entre as muitas perspectivas abordadas no contexto organizacional, a atitude invejosa assume um papel importante por impactar diretamente e de forma negativa o desempenho dos indivíduos na organização (GHADI, 2018; MARIS et al., 2016). Apesar de sua importância, os diversos esforços de pesquisa direcionados à inveja e suas implicações como campo de estudo são caracterizados por uma evidente limitação (LANGE et al., 2018), pois a área gerencial tem prestado pouca atenção a esse fenômeno, o que levou a uma escassez surpreendente de pesquisas na extensão comportamental-organizacional (GHADI, 2018; THOMPSON et al., 2015; COHEN-CHARASH, 2009).

Por ser considerada como uma emoção negativa que se acredita estar difundida no local de trabalho embora, venha sendo relutantemente ignorada e amplamente não reconhecida sua presença (GHADI, 2018; MISHRA, 2009), uma vez que pode causar sofrimento emocional por meio de comparações entre indivíduos, vindo a ameaçar sua saúde mental (HUH et al., 2018) e evidenciar uma piora no bem-estar (VERDUYN et al., 2015). Por essa razão a inveja é raramente mencionada nos livros de gestão, embora tenha uma forte, por vezes expressiva, influência sobre equipes, relações de trabalho, e sistemas organizacionais negativamente (HARNOIS et al., 2002).

Conviver com atitudes invejosas e suas ações destrutivas embora, também faça parte da condição humana são em parte criadas por nossos próprios sentimentos, resultados das próprias experiências observadas a partir do outro e, desencadeado por emoções ou reações comportamentais a estes. A emoção invejosa é tipicamente apresentada na literatura psicológica como uma emoção maliciosa e destrutiva, muitas vezes resultando em um comportamento prejudicial direcionado a pessoa invejada (SMITH et al., 2007). Essa subjetividade refere-se a uma experiência consciente do indivíduo a partir do auto relato de si, baseado em seus padrões, valores e crenças sobre uma vida feliz, apesar de avaliar o afeto e a satisfação como domínios específicos da vida (MELO, 2007).

A presença de atitudes invejosas em uma equipe, departamento ou mesmo empresa é extremamente preocupante porque ataca principalmente a capacidade de interação, a saúde mental e a qualidade satisfatória das relações interpessoais (HUH et al., 2018). Portanto, reconhecer e tomar consciência de que quando a inveja se desenvolve, a relação de uma pessoa com a outra é prejudicada (LANGE et al., 2016) se tem configurado de relevância considerável para o contexto de trabalho, pois uma organização não é uma entidade estável nem homogênea, mas sim um conjunto de processos em andamento de reconstrução e desconstrução de relações sociais (VIDAILLET, 2008) nas quais as emoções são inseparáveis do trabalho diário dos funcionários e desempenham um papel vital na maneira como os funcionários se comportam e reagem no mesmo (GHADI, 2018).

No contexto de trabalho em instituições de ensino superior, a inveja pode ser caracterizada como um estado negativo que tem influências contraproducentes sobre os vários resultados relacionados as atividades da organização (THOMPSON et al., 2015). A comparação social que produz inveja está vinculada a 
domínios que são importantes para o indivíduo em termos de sua identidade. Pois, a inveja produz impressões negativas sobre os outros, mina o sucesso por meio de estratégias agressivas que pioram o bemestar (CRUSIUS et al., 2017; LANGE et al., 2015b), ocasionado problemas como depressão, ansiedade, pânico, entre outros que podem se configura como ameaça evidente à saúde psicológica (HUH et al., 2018).

Nesse sentido, o presente estudo busca responder a seguinte questão de pesquisa: Existem diferenças na percepção que os professores universitários de instituições públicas paraibanas detêm sobre os construtos inveja em seu local de trabalho?. A relevância em estudar tal percepção no contexto de atuação profissional acadêmico se evidencia na possibilidade verificar se os resultados obtidos são consistentes com a literatura e por permitir compreender o construto na visão dos docentes nas instituições de ensino público, por ser descrito comumente comum um ambiente hostil e ameaçador.

Frente a isso, definiu-se como objetivo geral identificar a percepção que os professores universitários de instituições públicas paraibanas detêm sobre a inveja em seus locais de trabalho. Uma vez que, sentimentos destrutivos afetam a saúde geral dos indivíduos, sua capacidade de trabalhar produtivamente, seus relacionamentos com outros, além de custos relacionados ao baixo desempenho no local de trabalho (HARNOIS et al., 2000). Assim, presume-se que compreender e interpretar tal contexto a partir de uma investigação da percepção docente possibilitará estabelecer ações que possam vir a desencorajar condutas consideradas disfuncionais e improdutivas nos relacionamentos dentro deste meio.

\section{REVISÃO TÉORICA}

\section{Inveja, conceitos e tipos}

A tarefa de definir a inveja é claramente complexa e difícil. Em primeiro lugar, porque que as pessoas invejosas nem sempre são conscientes de que suas ações e motivos podem ser atribuídos a comportamentos invejosos. Em segundo por descrever uma diversidade conceitual que a envolve, o que gera dificuldade em compreender plenamente sua terminologia descritiva (VIDAILLET, 2008). A inveja tem sido categorizada como 'crise espiritual' pelos filósofos, 'pecado' ou 'vício' pelos moralistas, como uma 'emoção' por alguns psicólogos, como 'processos mentais' pelos psicanalistas. Tendo sido comumente usada para se referir a uma força capaz de destruir e atacar o próprio indivíduo ou as qualidades que este admira (BARROWS, 2002).

De acordo com Cukier (2011) a inveja adquire um aspecto diferente a depender do que se deseja enfatizar: é um tipo de dor psicológica sentida quando existe comparação com outras pessoas e, seu valor, autoestima e auto respeito começam a diminuir; é a observação daquilo que nos falta dolorosamente; sentimento que surge quando outra pessoa tem características superiores às si próprio; é também admiração e amor por aquilo que não se tem; é um sentimento de alegria ou prazer que designa o sofrimento ou infelicidade dos outros (Schadenfreude); é algo que nos toma quando observamos o sucesso dos outros.

Assim, a inveja pode ser compreendida como uma emoção ascendente (CORICELLI et al., 2010), por enfatizar elementos afetivos negativos desagradáveis, muitas vezes dolorosos e caracterizados por sentimentos de inferioridade, hostilidade e ressentimento produzidos pela consciência de outro (SMITH et 
al., 2007). Isso se deve ao fato de que a inveja influencia negativamente os colaboradores e suas organizações, uma vez que os indivíduos que experimentam tal emoção tem dificuldade de controlar, esconder ou mudar seus sentimentos (KIM et al., 2010) passando à expressa-la de forma direta, indireta, abertamente ou sutilmente (COHEN-CHARASH et al., 2007; DUFFY et al., 2012).

Embora, sem um alvo específico de desejo ou uma vítima essa emoção não tem como surgir e prosperar em um contexto social. Na perspectiva de Verdiani (2006) de um forma ou de outra, em maior ou menor escala todos sentem inveja em algum momento da vida o que dificulta seu reconhecimento e admissão diante de outros, sendo menos incomodo acreditar que o outro é que tem inveja de nossa vida. A emoção invejosa é tipicamente apresentada na literatura psicológica como uma emoção maliciosa e destrutiva, muitas vezes resultando em um comportamento prejudicial direcionado a pessoa invejada (SMITH et al., 2007).

O sentimento de inveja como parte da natureza humana tem sido discutido por vários autores, entre os quais Vries (1996) e Tomei (1994), que baseando seus estudos na psicanálise, reafirmam a questão que aponta a inveja como inerente ao comportamento do homem, representada pela falta de confiança e segurança em si próprio, e por sentimento de impotência frente ao outro, também está intimamente ligado à necessidade de status e por vezes a questões que não podem ser quantificadas, como as virtudes humanas e a sensação de injustiça, em que uma situação de privação de algo e de suposta injustiça institucional, interpessoal, ou social é suficiente para o aparecimento da inveja (TOMEI, 1994).

No campo da filosofia tem sido considerada como desvirtuo, sendo associada com a ingratidão e alegria pelo mal-estar alheio, que atormenta a si próprio com o desejo de destruir a felicidade do outro (BARROWS, 2002). Para Bonder (2004) a inveja é dolorosa e sempre envolve o desejo de possuir algo, que podem gerar decepção, vergonha, culpa, tristeza e por vezes admiração, podendo ser vivida como uma ameaça ou como uma doença. Para Tomei (2004), a inveja envolve três categorias especificas: (i) inveja sublimada, na qual os indivíduos sentem inveja, mas conseguem superar esse sentimento a utilizando para seu próprio crescimento. Tais indivíduos admitem que existem qualidades no seu objeto de inveja e as tomam como espelho para superar seus próprios objetivos; (ii) inveja neurótica, os indivíduos sofrem por sentirem inveja, embora não façam nada para mudar isso. Podem ser considerados sujeitos deprimidos, amargos e ansiosos; e, a (iii) inveja perversa, na qual são indivíduos invejosos que buscam destruir seu objeto de inveja. São difíceis de encontrar em organizações porque ao depreciar o alvo invejado terminam por destruir suas próprias relações de trabalho.

Para Lange et al. (2018) as teorias de inveja existentes são amplamente discrepantes, por não deixar claro se esta é uma construção uniforme ou tem formas distintas, sendo descrita pela literatura a partir de três teorias: a Teoria da Inveja Maliciosa que conceitua a inveja como uma emoção uniforme com consequências maliciosas (SMITH et al., 2007); a Teoria da Inveja Dual com duas formas distintas, das quais uma é benigna de caráter social e profissionalmente aceita segundo a qual não se quer destruir nada nem ninguém (VAN DE VEN et al., 2009) e a outra é maliciosa representada por "a nasty feeling that the visa is destroyed as another's conquest, and in some cases destroyed or otherwise" (VERDIANI, 2006) e, a terceira 
Teoria da Inveja da Dor que conceitua a inveja como uma emoção uniforme impulsionada pela dor que pode levar simultaneamente a consequências construtivas e destrutivas (TAl et al., 2012). A partir da Figura 1, proposta por Lange et al. (2018) é possível compreender que os autores postulam três componentes-chaves da inveja.

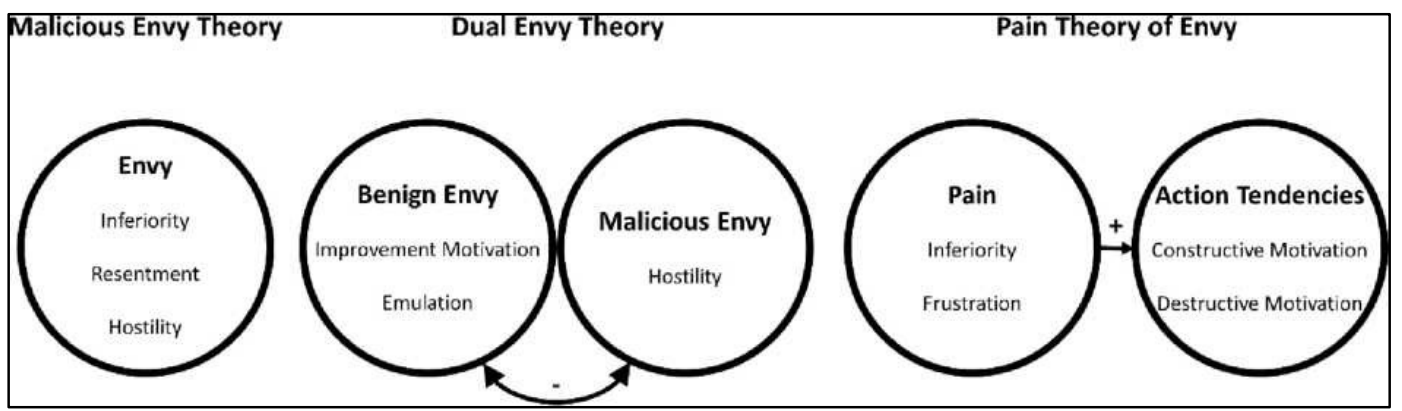

Figura 1: The three existing theories of envy. Fonte: Lange et al. (2018).

O lado esquerdo do modelo a descreve inicialmente como sendo compreendida como um sentimento de inferioridade, hostilidade e ressentimento causados pela vantagem desejável de outra pessoa. Características, admiração ou emulação pelo objeto da inveja, ainda não eram explicitamente incluídos nessa definição (LANGE et al., 2018). No meio apresentam-na de forma dual a partir de uma inveja benigna obtida quando o indivíduo avalia o status da pessoa invejada como merecido e a toma como parâmetro para alcançá-la também. Em contraste, está a inveja maliciosa que tem como foco de atenção a outra pessoa (CRUSIUS et al., 2014) e comportamentos direcionados a minar o sucesso do invejado (LANGE et al., 2015b). E, por fim no lado direito a inveja é descrita como uma dor ocasionada por uma comparação ascendente que incluem frustração, inferioridade e uma tendência motivacional tanto destrutiva como construtiva.

Segundo Klein (1991) a inveja é um sentimento por algo desejável que outra pessoa possui e desfruta de ter este algo ou estragá-lo. É uma emoção dolorosa e contraditória com base em uma experiência de falta e de comparação, um sentimento endêmico vivido a partir de situações de frustração na vida (BONDER, 2004), que normalmente envolve um desejo de ter o que o outro possui. Representada por uma falta de confiança, segurança em si próprio, de impotência frente ao outro (RAWLS, 2000), de inferioridade e de vivenciar uma situação de injustiça (SMITH et al., 1999).

No nível organizacional, sentimentos de inveja são vistos como uma forma de criar entre funcionários conflitos, prejudicar relacionamentos, o desempenho organizacional, separar e sabotar equipes, e seus esforços (MENON et al., 2010). No individual, esses sentimentos invejosos refletem em outros colegas e sobre si, tornando-os menos satisfeitos, com baixa autoconfiança, depressão e estresse, podendo ignorar ou mesmo interromper seu próprio desempenho e, provavelmente, sua futura carreira profissional (VEIGA et al., 2014). Essas situações indicam problemas de saúde e fazem com que os funcionários se sintam doentes. Uma vez que, as emoções têm repetidamente comprovado sua influência de forma favorável sobre a saúde (STEPTOE et al., 2008; PRESSMAN et al., 2005; COHEN et al., 2003; PETTIT et al., 2001). Sobre a sensação de bem-estar, satisfação com a vida e sua visão de felicidade (MILFONT et al., 2009). 


\section{Inveja no Local de Trabalho: Uma Visão Geral}

Não é o foco deste estudo discutir a inveja patológica, mas a inveja comum, o tipo de inveja que é provável que afete a maioria dos indivíduos no ambiente de trabalho, e que ocorre quando menos se espera ao ouvir que um colega foi promovido ou que o outro foi felicitado por uma nova conquista profissional. No ambiente de trabalho a inveja é uma emoção comum, engendrada por demandas de alta produtividade, competição por recursos limitados, oportunidades de promoções, comparações de desempenho, entre outros (STERLING et al., 2016).

As pesquisas sobre a inveja no local de trabalho e seus resultados têm sido limitadas e concentradas predominantemente em sua natureza destrutiva, como a schadenfreude (VAN DIJK et al., 2006), a sabotagem de colegas de trabalho (COHEN-CHARASH et al., 2007; O'NEILL et al., 2011), o comportamento não ético (GINO et al., 2009), na eficácia do trabalho do grupo (DUFFY et al., 2000), entre outros. Uma vez que, os locais de trabalho fornecem inúmeros gatilhos para o fomento da inveja, a exemplo, das avaliações e remuneração baseada em desempenho, além das próprias interações sociais (SHAW et al., 2009). Apesar dessa visão destrutiva existem estudos que evidenciam que a inveja também pode ser funcional (COHENCHARASH, 2009; DUFFY et al., 2008; TAI et al., 2012; VAN DE VEN et al., 2009; VECCHIO, 1995), uma inveja benigna que pode motivar o indivíduo invejoso a melhorar sua posição na organização para conseguir o que deseja, como um elemento motivador para um maior envolvimento comportamental com o trabalho (BOARDMAN et al., 2016).

As condutas prejudiciais realizadas pelo invejoso podem ser compreendidas de maneira geral como um mecanismo no qual as pessoas podem encontrar justificativas para cometer atos antissociais sem se sentirem culpadas ou censuradas e com isso, "desprender-se ou desengaja-se dos próprios padrões morais para cometer atos deliberadamente sem autocondenação" (IGLESIAS, 2008), os quais pode ser manifesto ou oculto em relação às conquistas de outros que integram o mesmo núcleo social. Apresenta-se a partir das relações de estados experienciais, emocionais e de espírito como: ansiedade, sofrimento, desejo, ódio, ressentimento, solidão, desgosto, psicose, motivação, autodestruição, culpa, entre outros (NINIVAGGI, 2010). Não sendo tão fácil de categorizar em parte porque, ao contrário de sentimentos como medo ou raiva, por exemplo, os sentimentos invejosos são menos expressivos, identificável e indistinguível em termos de reconhecimento dos efeitos presente em seus comportamentos sobre outros (VIDAILLET, 2008).

Tais ações podem até ser parcialmente inconscientes para os próprios indivíduos invejosos e seu comportamento pode ser condicionado pela inveja sem eles perceberem. Quando a inveja é ativada em níveis inconscientes ou conscientes, é experimentada como dolorosa, angustiante e insatisfatória. O invejoso, em meio à inveja inconsciente, vê o mundo e os outros como negativos, vazios, insatisfatórios, amargos, injustos e inatingíveis. Ao criar um estado de sofrimento auto imposto que é amargurado e sombrio (NINIVAGGI, 2010). Geralmente, a inveja é experimentada quando de acordo com Dogan et al. (2001): desejase possuir objetos materiais ou atributos pessoais de outra pessoa; avalia-se inferiormente acerca do valor de si baseado em uma comparação social com outro colega; sente-se infeliz com o que outro colega tem; e, 
ao desejar que outros percam as vantagens ou não as tenha em primeiro lugar.

A inveja penetra gradual e inevitavelmente no ambiente da organização sendo frequentemente descrita como um 'veneno'. O que a torna tão tóxica é difícil de detectar no início, uma vez que se expressa de forma oculta, muitas vezes inconsciente, e de maneira disfarçada. Por exemplo, pode manifestar-se sob a forma de agressividade em relação a uma pessoa e, no entanto, é difícil saber com certeza que essa agressividade é causada pela inveja. Surge em sujeitos que são levados a imaginar que podem ou devem estar no lugar de outra pessoa, mas não estão assim, o lugar do outro passa a ser algo invejável (VIDAILLET, 2008).

Em uma organização, esse 'algo' pode ser um melhor salário (ou recompensa), poder ou status. As pessoas que encontram satisfação em sua carreira, que não são atormentadas por frustração inexpressiva e que aceitaram suas próprias limitações, provavelmente não sentirão inveja (GHADI, 2018). Indivíduos que, ao contrário, carecem de autoconfiança e veem os outros como seres completos que não possuem limitações, podem assumir caraterísticas de uma pessoa invejosa, considerando que pode se sentir desapropriado e desvalorizado pela organização.

A temática no local de trabalho é ainda mais evidente e reforçada quando o objeto da inveja é relevante para o status social (CRUSIUS et al., 2017; FISKE, 2010; LANGE et al., 2015b) e quando o invejoso percebe que a pessoa invejada é semelhante a si (HENNIGER et al., 2015; SCHAUBROECK et al., 2004), uma vez que os indivíduos têm um forte desejo por tal status (ANDERSON et al., 2015). Assim, como as práticas de gestão na organização e, em particular, a forma como os processos são conduzidos, fornecem outras oportunidades de desencadear inveja entre os funcionários, a exemplo, de quando uma pessoa é promovida e não a outra, pois uma lacuna se abre entre duas pessoas auto comparáveis (VIDAILLET, 2008).

Segundo Sias et al. (2004) a promoção de um dos funcionários na organização para uma posição de autoridade formal em detrimento de outro se configura como uma das principais causas da deterioração da amizade no local de trabalho. Esse desgaste das relações entre indivíduos pode ser interpretado como uma manifestação de inveja. É importante notar, no entanto, que uma promoção não aciona sistematicamente a inveja. Dois fatores parecem ter um papel decisivo frente a essa situação: altas expectativas de promoção e um alto nível de similaridade entre o indivíduo rejeitado e o indivíduo promovido (SCHAUBROECK et al., 2004).

Os sentimentos de inveja vivenciados pelos sujeitos estão enraizados na ideia de que tudo o que o outro possui deve ser seu por direito. Indivíduos invejosos se sentem privados daquilo que as pessoas invejadas possuem e ver isso no outro causa o sofrimento insuportável (VIDAILLET, 2008). Sendo, o único objeto capaz de satisfazer o invejoso o que o outro possui, o que explicaria o desejo de adquiri-lo para si mesmo ou privar o invejado do mesmo. Da mesma forma, em que pode induzir a hostilidade e comportamentos ressentidos, sentimentos de inferioridade, baixa autoestima, depressão, neuroticismo, ciúmes, entre outros (DUFFY et al., 2012; MEDEIROS et al., 2016).

Organizações que adotam práticas gerenciais e motivacionais que se baseiam na exploração da inveja desempenham um jogo perigoso. Quando a inveja é permitida em uma organização, dificulta a fluidez 
relacional e os indivíduos são levados a negligenciar aspectos, como a criatividade ou a colaboração, que são essenciais para a sobrevivência desta (VIDAILLET, 2008). Para Vecchio (1995) o desafio consiste em permitir que os indivíduos superem situações que os levaram a duvidar de suas próprias competências e habilidades por meio da promoção da autonomia do emprego e da minimização das oportunidades de comparação no intuito de reduzir às probabilidades de surgimento da inveja.

Considerando o exposto, é possível inferir que a inveja derivada de uma comparação entre um invejoso, um objeto de inveja (uma conquista, característica ou posse) e uma pessoa invejada (LANGE et al., 2018; MICELI et al., 2007; SMITH et al., 2007). Tal situação adquire ainda mais relevância quando o indivíduo percebe que a pessoa invejada tem características semelhantes a si (HENNIGER et al., 2015; SCHAUBROECK et al., 2004), pois a atitude que uma pessoa tem em relação à sua própria vida afeta a forma como está vivencia seu estado de saúde, por ser um possível indicador de comportamentos futuros, como o suicídio e, da própria satisfação com a vida por estar relacionada a fatores psicológicos (depressão, estresse e ansiedade) que afetam diretamente a saúde e o absenteísmo no trabalho (BUCZAK-STEC et al., 2018).

\section{METODOLOGIA}

A pesquisa se desenvolveu a partir de um conjunto de procedimentos e técnicas com o propósito de compreender a percepção dos professores sobre a inveja no contexto de ensino superior público paraibano. Para viabilizar a consecução dos objetivos, este estudo se caracteriza como uma pesquisa com finalidade exploratória que conforme Sampieri et al. (1991) têm o intuito de realizar um levantamento acerca das concepções relacionadas ao fenômeno estudado. E, descritivo com o desígnio de descrever características de um fenômeno, população ou relações entre variáveis (GIL, 2008). Assim, a finalidade desta pesquisa é estudar as características de um grupo específico, a partir de uma abordagem qualitativa.

Para a realização deste estudo aplicou-se a técnica de associação livre, que de acordo com Merten (1992) originou-se da chamada teoria do associacionista da memorização, com a finalidade de descobrir o conteúdo ideacional evocados pelos indivíduos. Nesse sentido, a TALP torna por meio de projeções conscientes as condutas, reações evocações e a percepção do indivíduo sobre uma determinada temática em estudo (COUTINHO, 2001) permitindo assim evidenciar, observar, registrar e, obter uma comunicação verbal sobre o fenômeno em análise (MERTEN, 1992), os quais podem ser verbais (frases, palavras ou expressões) ou não verbais (figuras ou imagens). Desse modo, demostra-se como um instrumento que se apoia em pesquisa do tipo investigação aberta, permitindo evidenciar diferentes universos semânticos comuns de palavras.

O método foi aplicada a partir de um survey online, ressalta-se que esse tipo de pesquisa possui vantagens, como sua versatilidade de questionar ao invés de observar e, limitações que de acordo com Cooper et al. (2016) envolvem a qualidade dos dados e a quantidade de informações obtidas, as quais dependem da capacidade e disposição do participante e em contribuir com a execução da pesquisa. Participaram deste estudo 69 professores universitários distribuídos entre as quatro instituições ensino superior públicas (IES) do Estado da Paraíba. 
No instrumento de coleta foi apresentado uma palavra estímulo e logo abaixo disposto espaços de respostas numeradas, para que os sujeitos anotassem suas respostas em sequência, preservando o critério de ordem de aparecimento destas, procedimento necessário, sobretudo, para a identificação da estrutura e esquemas cognitivos. A questão padronizada para a aplicação da técnica foi solicitar ao sujeito que: 'Se eu falar a palavra INVEJA em seu local de trabalho o que passa na sua cabeça?. Indique 3 palavras'. Cabe ressaltar que o número de respostas solicitadas aos entrevistados é variável sendo, suficiente três respostas para formulação de esquemas cognitivos (GUIMELLI, 2003).

Para o processamento dos dados, utilizou-se o software IRAMUTEQ versão 07, o programa faz inicialmente a listagem de todas as palavras que se encontram no banco de dados, assim como as frequências de aparecimento permitindo as análises estatísticas de textos produzidos. Para a análise o primeiro passo consistiu em preparar o banco de dados correspondente a cada estímulo indutor utilizado na pesquisa. Assim, para o estímulo foi criado um arquivo dicionário no qual se inseriu as respostas evocadas por todos os pesquisados com relação ao respectivo termo de estímulo. Nessa etapa o programa fez a leitura do texto e o cálculo dos dicionários, reconhecendo as unidades de contexto iniciais (UCI), para a primeira fragmentação do texto, além de agrupar as palavras por radicais também chamadas de formas reduzidas, para em seguida calcular a sua frequência.

A segunda etapa consistiu em classificar as respostas por ordem das mais frequentes, que se enquadram na mesma categoria descritas como unidades de contexto elementares (UCE), para se agrupar a essas as palavras de maior frequência e de similaridade semântica. Dessa forma, junta-se por agrupamento as palavras com similaridade de semântica ou afinidades de sentido, o que permite verificar semelhanças e diferenças nas respostas evocadas pelos sujeitos. Assim, o dicionário (categoria) devem ser estruturados seguindo o arranjo das respostas aos estímulos pré-estabelecidos inicialmente, de modo separado. As categorias podem ser estabelecidas na fase exploratória ou a partir da coleta dos dados, para realização deste estudo se optou pela categorias pós-coleta por serem mais especificas, concretas e por critério léxico (MINAYO, 2010).

Com relação a codificação utilizou-se quatro asteriscos, seguido pelo código do item em análise em seguida. Para a parte analítica das palavras foram usadas a classificação hierárquica descendente, análise de similitude e nuvem de palavras, que agrupa, e organizam graficamente de acordo com a frequência o cálculo das matrizes de dados na classificação das UCE, em função dos seus respectivos vocabulários, permitindo a descrição das classes obtidas, principalmente, pelos seus vocabulários característicos (léxico) e pelas suas palavras com asterisco (variáveis).

\section{RESULTADOS E DISCUSSÕES}

\section{Análise textual básica}

Quanto a caracterização dos sujeitos se pode observar que dos 69 docentes respondentes, estes possuem em média 23,4 anos de idade $(D p=6,65)$ sendo $46 \%$ do sexo feminino. Com relação a parte analítica 
iniciou-se a partir do corpus de segmento de texto. Para a parte lexical clássica e lexicografia básica, realizouse uma análise estatística simples do corpus, com o quantitativo efetivo das formas ativas, suplementares e lista de hápax. O resultado é apresentado na Gráfico 1.

Pode-se observar pela análise realizada no Gráfico 1 que a média de formas por texto foi de 110 processamento do corpus (unidade lexical) realizado em 23 segundos sendo classificadas 208 UCE, das quais 79 foram aproveitadas (apareceram apenas uma vez em todo o corpus), ou seja, $71,82 \%$ do total. Para a criação de um dicionário de palavras, o programa utiliza o teste qui-quadrado $\left(\chi^{2}\right)$, que revela a força associativa entre as palavras e a sua respectiva classe. Essa força associativa é analisada quando o teste for maior que 3,84, representando $p$ (WACHELKE et al., 2012).

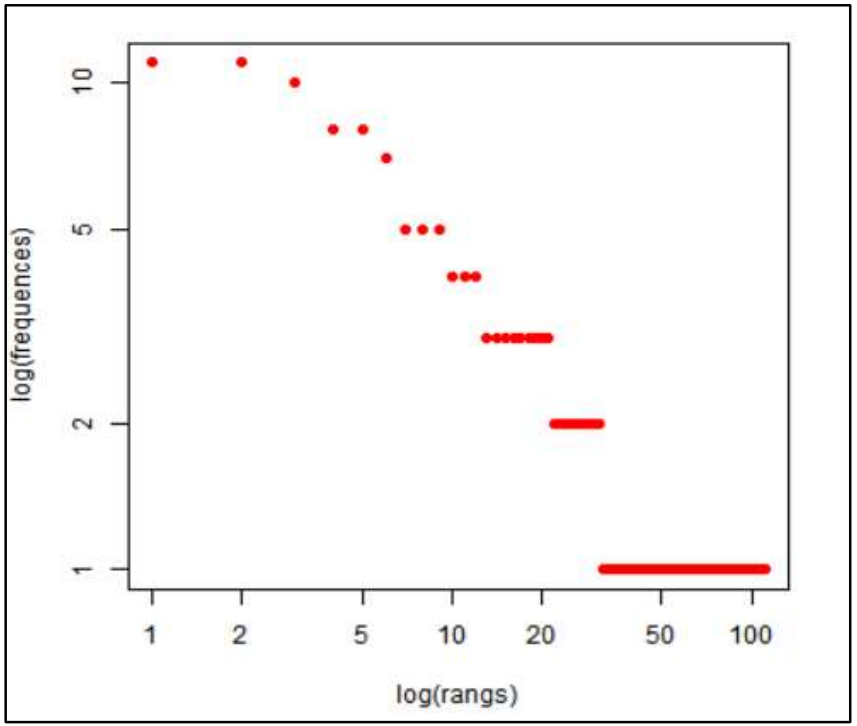

Gráfico 1: Apresentação dos resultados da análise estatística textual.

Resumo: Número de textos: 1; Número de ocorrências: 208; Número de formas: 110; Número de hápax: 79 (37, 98\% de ocorrências - 71, $82 \%$ de formas).

A partir do gráfico acima se percebe que existem muitas formas de palavras que repetem pouco (eixo vertical) e pouquíssimas que se repetem com muita frequência (eixo horizontal), indicando uma dispersão dos termos informados e utilizadas na compreensão do que se configuraria como 'inveja' para os sujeitos em análise. Isso pode ser resultado de um desacordo sobre como conceituam a inveja. Apesar de sua importância, os diversos esforços de pesquisa voltados ao estudo da inveja podem ser caracterizados por uma evidente limitação que enfraquece sua utilidade (LANGE et al., 2018).

Esse desacordo conceitual sobre a inveja pode ser evidenciado nos estudos de Miceli et al. (2007) e Smith et al. (2007), que a descrevem como puramente hostil. Já autores como Lange et al. (2015a), Van de Ven et al. (2009) a distinguem como sendo vista sobre uma perspectiva benigna e maliciosa. Zeelenberg et al. (2009) e Tai et al. (2012) por outro lado a conceituam como uma unidade de emoção envolvida em um sentimento de dor. Por conseguinte, essa divergência de ideias sobre a natureza conceitual da inveja, a qual fica clara à medida que os pesquisadores usam componentes diferentes para estudá-la, possivelmente poderia ser a razão para essa conceitualização variada em relação a inveja que permeia a literatura.

Outro importante resultado da pesquisa, é a análise de similitude com as principais palavras 
destacadas pelos sujeitos. Este gráfico facilitar a visualização da informação ao transformar dados abstratos em gráficos ou imagens, assim a análise de similitude se baseia na teoria dos grafos e possibilita identificar as ocorrências entre as palavras. Esse resultado traz indicações da conexidade entre as palavras, ao permitir a identificação da estrutura de um corpus textual, distinguindo as partes e especificidades comuns das variáveis descritas (WACHELKE et al., 2012).

Para realizar essa análise foram utilizados para essa amostra, os vocábulos com maior índice de frequência e relevância. Dentre os termos analisados quatro vértices emergiram como resultado do valor semântico que possuíam devido a quantidade de agrupamentos de vértices que englobavam, e pela quantidade de ligações (arestas) que se conectam com outros vértices (Gráfico 2).

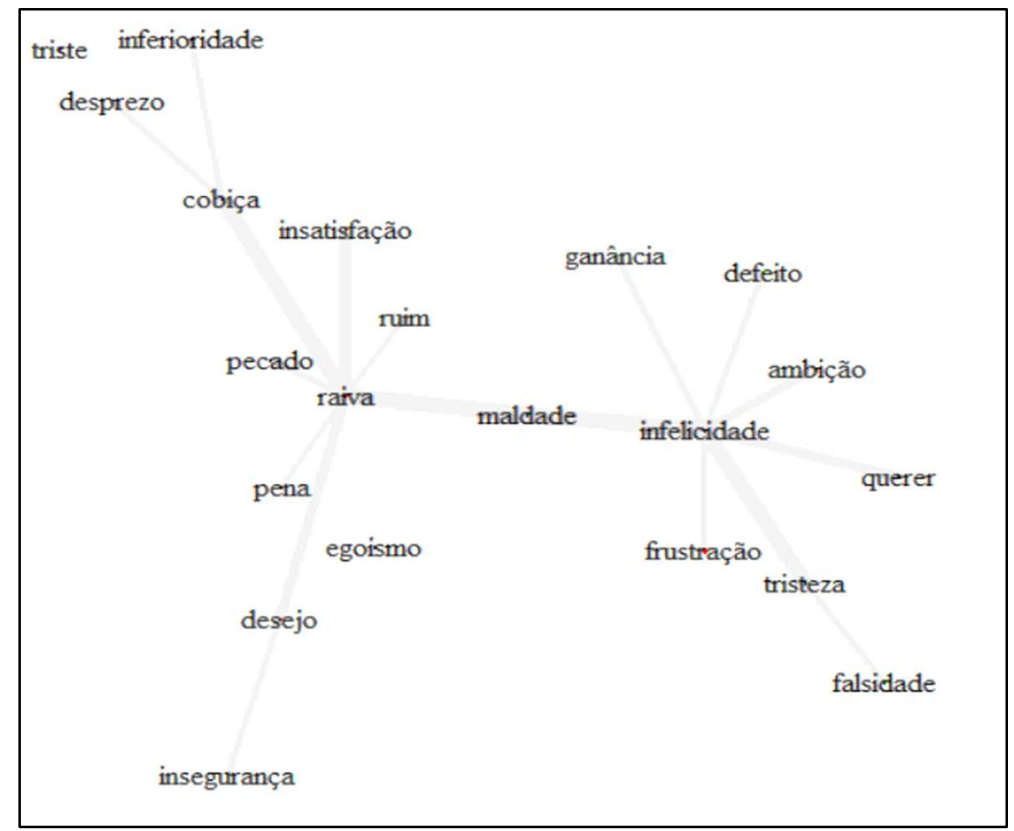

Gráfico 2: Agrupamentos de termos em nível de proximidade e similitude.

$\mathrm{Na}$ análise de frequência foi identificado que os termos 'cobiça', 'raiva', 'maldade e infelicidade' são as quatro palavras mais frequentes, respectivamente, de ocorrências. Observa-se que os termos se ligam a outros por meio de fios cinza-claro. A espessura desses 'fios' representa o grau de conexão entre os termos observados. Dessa maneira, observa-se que 'cobiça' se conecta com termos como, 'inferioridade', 'desprezo' e 'triste' (vide Gráfico 2). Esses termos aparecem em agrupamentos externos ao agrupamento central. Já a 'raiva' possui ligação com 'insatisfação', 'pecado', 'ruim', 'pena', 'desejo', 'insegurança', 'egoísmo' e em maior grau de proximidade e similitude mais próxima da 'maldade'. Em relação à 'maldade', percebe-se que está mais intensamente conectado à 'infelicidade', que por sua vez, está conectado à 'ambição', 'tristeza', 'querer', 'frustação', 'ganância' 'defeito' e 'falsidade'. Isso significa que os termos ocorrem de forma conjunta no corpus. Tal visualização só é possível graças a verificação da espessura das linhas que conectam os termos.

Esse gráfico de similitude apresenta os indícios das correlações temáticas existentes entre os vocábulos. Assim, é possível observar que os termos mais periféricos em agrupamentos, se conectam ao conjunto principal, mesmo apresentando números inferiores de ligação, como o vértice 'egoísmo', por exemplo. Outro ponto importante da análise a se destacar é o tamanho da área da circunferência, uma vez 
que que se relaciona com a maior frequência do termo. Assim, observa-se que apesar de alguns termos apresentarem um baixo índice de frequência, como 'egoísmo' (3 ocorrências) e triste (3), este apresenta um relativo grau de conexidade com o vértice 'raiva' e 'cobiça', respectivamente.

Assim, a inveja é um sentimento que toda possuem seja em grau mais evidente ou não. Seu caráter dissimulado e paciente dificulta sua percepção pela maioria das pessoas, uma vez que pode assumir condutas distintas, como: indiferença, raiva, cobiça, ironia, maledicência, calúnia, infâmia, indignação, deboche, ódio, desrespeito e, tantos outros, que a depender da situação e das circunstâncias do contexto social surge a partir de conflitos de relacionamentos resultantes da falta de compreensão e respeito mútuo, de emoções como raiva, ressentimento, culpa ou desejo de vingança que vão deteriorando os relacionamentos do grupo e, de comportamentos sociais subsequentes no local de trabalho, a exemplo da desvalorização do invejado, justificação moral da ação, uso de linguagem eufemística ou rotulagem, distorção das consequências incluindo a minimização das ações comportamentais (DUFFY et al., 2012), por dificultar a capacidade de outros de manter relações interpessoais positivas, de sucesso profissional e reputação favorável (DUFFY et al., 2002).

Esse invejar evidenciado no local de trabalho oferece inúmeras oportunidade de um indivíduo fazer comparações sociais, baseadas em informações imprecisas e exageradas que se tornam mais distorcidas a medida que o tempo passa. Assim, negligenciar o papel da inveja na vida organizacional limita a compreensão de uma multiplicidade de eventos e fenômenos organizacionais em vários domínios das organizações, por exemplo, desempenho individual, eficácia da equipe, clima corporativo, sistemas de gerenciamento de recursos humanos (LANGE et al., 2018).

Em seguida, realiza-se o processamento e o agrupamento quanto às ocorrências das palavras, a partir da classificação hierárquica descendente (CHD) se cria o dendograma das classes. Esta figura, além de apresentar as classes, demonstra a ligação entre elas e o quanto estão associadas entre si. Cada classe possui uma cor diferenciada, e as UCE de cada uma possuía a mesma cor da classe, conforme a Figura 2.

A classificação hierárquica descendente identifica a raiz semântica das palavras em um determinado contexto e, em seguida, extrai as classes de enunciados representativos. Dessa forma, as classes lexicais foram formadas pelo conjunto de vocábulos que têm sua associação estatisticamente significante, cada conjunto representando um assunto, resultado da aproximação de significados das palavras das classes, sendo descrito pelo vocabulário que os define. O corpus foi dividido em duas classes, conforme pode ser observado na Figura 2, a seguir.

A partir do dendograma da Figura 2 foi possível visualizar as palavras que obtiveram maior frequência média entre si. Pela leitura das palavras em destaque, e de sua inserção nos segmentos dos textos, foi possível verificar que esse conjunto de análises inicial, mediadas pela estatística lexical e a construção das classes pelo método de Reinert, feitas pelo IRAMUTEQ, resultou em indicativos para o surgimento das categorias para discussão no estudo e, após uma pré-análise qualitativa, os dados foram codificados, classificados e categorizados, como se observa no Quadro 1 em duas classes. 


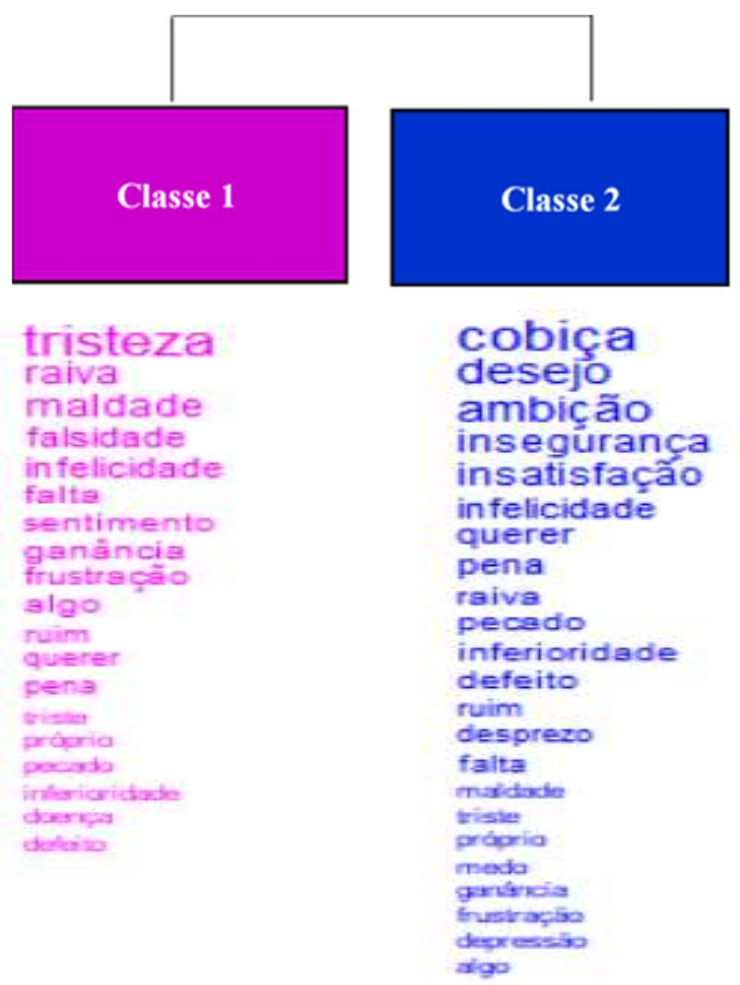

Figura 2: Dendograma das classes fornecidas pelo software IRAMUTEQ.

Quadro 1: Categorias utilizadas no estudo resultantes das técnicas de análise empregadas no conteúdo das entrevistas

\begin{tabular}{|l|l|}
\hline Categorias Temáticas & Classes pelo IRAMUTEQ \\
\hline Inveja na percepção emocional & Classe 1 \\
\hline Inveja na percepção dolorosa & Classe 2 \\
\hline
\end{tabular}

De acordo com as análises das categorias que emergiram dos termos usados pelos sujeitos acerca do construto 'inveja' classificados de acordo com o IRAMUTEQ percebe-se que para os sujeitos a inveja é percebida por meio de duas classes categóricas: emocional e dolorosa. Na classe 1 a inveja é percebida como uma reação emocional negativa que resulta de comparações sociais indesejáveis, que podem ocorre quando o indivíduo A se compara com o indivíduo B e percebe que o indivíduo B é semelhante e tem algo que é desejado pelo indivíduo A, que também é essencial para o autoconceito do indivíduo A (COHEN-CHARASH et al., 2007). Para Lange et al. (2018) a inveja está entre as forças emocionais mais poderosas da natureza humana, uma vez que as pessoas que são mais propensas a fazer comparações com outros semelhantes experimentam uma inveja mais intensa.

Desse modo, percebe-se a inveja expressa pelos pesquisados em seu local de trabalho como um conjunto de 'emoções desagradáveis' a exemplo da raiva, ódio, egoísmo, entre outros estão presentes de forma naturais nas relações estabelecidas nesse contexto pelos pesquisados. Tais eventos afetivos podem ser utilmente empregados para a compreensão da influência das emoções sobre comparações sociais desfavoráveis. Para Vidaillet (2006) a experiência da inveja no local de trabalho foca em quem as pessoas são profissionalmente, quem elas querem ser, acreditam ser e o que falharam em se tornar.

Embora, o invejar ainda seja vista como socialmente um tabu, tornando-a particularmente negligência por seus membros e até mesmo pela própria organização. Dentro dos contextos organizacionais, existem inúmeros cenários (por exemplo, promoções, aumentos salariais, bônus, reconhecimento de 
desempenho) que são susceptíveis de provocar comparações sociais e gerar sentimentos de inveja entre os funcionários com consequências altamente destrutivas que podem atingir qualquer um dentro da organização (DUFFY et al., 2000).

Na classe 2, a inveja tem uma representação mais focada para seu lado doloroso. Para Lange et al. (2018) a teoria da inveja da dor incluiu itens referentes a inferioridade, frustração, ressentimento, vergonha e injustiça. Além disso, uma vez que as tendências de ação incluíam apenas o desejo e a emulação, refletindo o componente de comparação construtiva ao mesmo tempo em que se antecipava ao componente de sentimento destrutivo proposto pela Teoria da inveja da Dor evidenciada a partir de uma emoção uniforme que pode levar a consequências construtivas e destrutivas (TAl et al., 2012).

Essa percepção da inveja voltada para a teoria da dor pode estar associada a uma motivação para diminuir o status de outra pessoa (LANGE et al., 2015b), embora possa assumir uma lado benevolente, no qual o invejoso pode considerar a pessoa invejada como um meio de melhorar suas atitudes tanto para si quanto diante de outros, que pode ocorrer tanto com uma intenção benigna, implicando um desejo de melhorar a si próprio imitando as ações da pessoa invejada quanto maliciosa, ao envolver pensamentos hostis ou intenções voltadas a prejudicar outros.

Cabe ressaltar que a percepção dos respondentes acerca da inveja associando-a a emoções como raiva, frustação, maldade e infelicidade, confunde a inveja com estas emoções ao nível de mediação e, portanto, torna mais complicado avaliar se a visão emocional da inveja reflete uma invejar transmutado ou oculto por qualquer outra emoção distinta. Para Lange et al. (2018) décadas de pesquisas realizadas sobre a inveja deixam com um campo conflituoso sem uma teoria abrangente que simultaneamente explique-a a partir de seu núcleo emotivo e dos diversos elementos motivacionais que a compõe. A teoria da inveja da Dor propõe ainda que a dor pode ser primária e ocorrer temporalmente, o que pode então causar inveja benigna e maliciosa (ZEELENBERG et al., 2009), 2017; TAl et al., 2012). Por fim, optou-se pela nuvem de palavras para facilitar a visualização dos termos mais utilizados. Ressalta-se que a título de melhor expressão visual, a amostra foi delimitada as palavras mais frequentes dentro do corpus (Figura 3).

A Figura 3 apresenta os termos mais frequentes com o tamanho de fonte maior. Quanto maior a fonte do termo na figura, maior sua frequência na amostra, assim como quanto menor a fonte, menor sua presença. Assim, pode-se perceber que as seis primeiras palavras de maior incidência aparecem na seguinte ordem decrescente: cobiça, raiva, maldade, infelicidade, desejo e tristeza. Enquanto, que os seis menores em termos de frequência, que aparecem com fonte menor, são eles: querer, pena, ambição, ruim, insatisfação e falsidade. Nesse sentido, tal análise é importante para elucidar, num conjunto textual, quais são os temas mais percebido pelos sujeitos relacionados aos termos inveja em seu local de trabalho, permitindo ao pesquisador identificar quais são os principais termos de determinado conjunto de dados textual que vieram como resposta a associação livre realizada.

Percebe-se que para os sujeitos a inveja é uma emoção que está associada a afecções dolorosas e negativa e pode ser evidenciada em seu local de trabalho. $\mathrm{O}$ invejar está frequentemente associado um ressentimento direcionado a pessoa inveja podendo até se transformar em ódio. Sentimento que também 
pode ser acompanhado de raiva quando a pessoa invejosa se sente injustiçada frente aos ganhos obtidos pelo seu objeto de inveja. Assim, como pode ser resultado de uma insatisfação com a vida em geral, o sistema, as condições que beneficiam alguns e não outros, que pode vir acompanhado de raiva e amargura em relação à vida e ao destino, em que posses, talentos e qualidades são distribuídos de forma desigual (VIDAILLET, 2008). Cohen-Charash et al. (2007) também argumentam que uma situação injusta pode exacerbar os efeitos negativos da inveja nos comportamentos interpessoais.

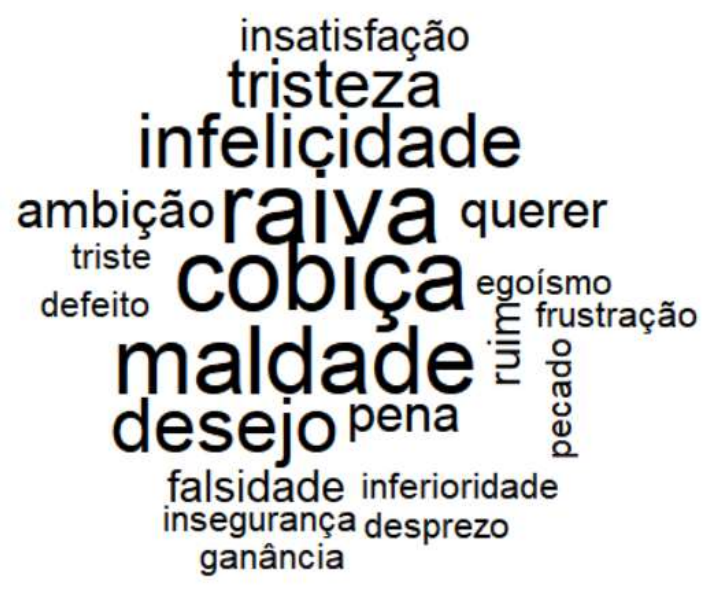

Figura 3: Nuvem de palavras da amostra.

A inveja também pode ser experimentada como um desejo intenso acompanhado de um sentimento de frustração expressa por meio da cobiça do que o outro possui, evidenciada não só pela privação de alguma coisa, mas também porque o outro não sofre o mesmo. Dentro do contexto organizacional o problema não é tanto a existência ou não da inveja, pois esta é inerente ao comportamento dos indivíduos em um grupo, em particular nos ambientes em que os indivíduos são objeto de comparações e avaliações, o que aparenta ser uma característica fundamental na maioria das organizações, mais sim as práticas que buscam estimular constantemente seus colaboradores para uma busca interminável por melhor desempenho e status. Para Vidaillet (2008) explorar a inveja para induzir os funcionários a melhorar sua produtividade e buscar constantemente melhores resultados pode parecer coerente, no entanto, essa prática de gestão apresenta enormes riscos para as relações socias tanto interna quanto externamente a organização.

\section{CONCLUSÕES}

Em muitas organizações os colaboradores se envolvem em interações próximas e frequentes com seus colegas de trabalho. Uma vez que, muitas pessoas gastam boa parte de suas vidas no trabalho do que em outros domínios de vida. Assim, os locais de trabalho acabam por ser um contexto propício para o estabelecimento de inúmeras relações sociais, as quais podem oferecer oportunidades abundantes para comparações sociais entre seus pares. Essas comparações sociais, embora às vezes ocorrem em particular, muitas vezes ocorrem em público e colocam o status social dos indivíduos em evidência. Por estas razões, não deve ser surpresa que a experiência da inveja na vida organizacional seja considerada relativamente comum. 
De fato, as organizações muitas vezes desenham e usam sistemas que implicitamente induzem a inveja para motivar os funcionários a níveis mais elevados de desempenho e no contexto de ensino superior público não é diferente. Por meio desta pesquisa foi possível percebe o local de trabalho dos professores universitários como sendo um terreno fértil para a inveja. Pois, em nível organizacional, sentimentos de inveja são vistos como uma forma de criar conflitos entre funcionários, prejudicar relacionamentos, separar equipes, sabotar os esforços e prejudicar o desempenho organizacional.

A inveja a partir deste estudo pode ser compreendida como uma emoção ascendente, por enfatizar elementos afetivos negativos desagradáveis, muitas vezes dolorosos caracterizados por sentimentos de inferioridade, hostilidade e ressentimento produzidos pela consciência de outro. Que em nível individual, podem refletir em outros colegas e sobre si, tornando-os menos satisfeitos, com baixa autoconfiança, depressão e estresse, podendo ignorar ou mesmo interromper seu próprio desempenho e, provavelmente, sua futura carreira profissional. Isso se deve ao fato de que a inveja influencia negativamente os empregados e suas organizações, uma vez que os indivíduos que experimentam tal emoção têm dificuldade de controlar, esconder ou mudar seus sentimentos passando a expressá-la de forma direta, indireta, abertamente ou sutilmente.

Como consequência disso pode-se provocar fortes reações emocionais no intuito de classificar ou diminuir o status de outros bem-sucedidos (inveja). E, assim, pode induzir a hostilidade e comportamentos ressentidos, sentimentos de inferioridade, baixa autoestima, depressão, neuroticismo, ciúmes, entre outros. Propondo que a inveja no local de trabalho desempenha um papel emocional disfuncional, segundo o qual os indivíduos ao manifestarem sentimentos invejosos podem minar sua satisfação com a vida e, consequentemente, desencadear problemas relacionados com sua saúde mental.

Com relação as limitações para realização da pesquisa pontuam-se a dificuldade de analisar grupos de termos que possuíssem representação semântica. Percebeu-se que o software é excelente para termos isolados, porém possui limitação na análise de palavras compostas. Outro ponto limitante foi a customização dos gráficos gerados. Como sugestão de estudos futuros, indica-se aprofundar as análises estatísticas do método e realizar outros tipos de estudos em conjunto com o software IRAMUTEQ.

Por fim, considera-se que percepção dos professores universitários sobre a palavra 'inveja' se encontra relacionada as emoções expressas na vida cotidiana e comportamental destes, uma vez que alguém pode ser chamado de 'invejoso' somente por outras pessoas associariam o seu comportamento à inveja. Embora, possa não existir qualquer ligação entre o que a pessoa sente conscientemente e o fato de que seu comportamento é motivado pela inveja. Bem como pela falta de consistência conceitual sobre a terminologia da palavra na percepção destes. Embora, ainda haja muito a ser feito tanto conceitual quanto empiricamente em termos de compreensão e consequências da inveja local de trabalho. O presente estudo contribui com a compressão do termo inveja na percepção dos professores universitários em seu local de trabalho, uma vez que não se buscou classificá-los quanto ao seu nível de inveja, mas trazer de forma explicita como a inveja vem sendo compreendida dentro do contexto de ensino superior público. 


\section{REFERÊNCIAS}

ANDERSON, C.; HILDRETH, J. A. D.; HOWLAND, L.. Is the desire for status a fundamental human motive? A review of the empirical literature. Psychological Bulletin, v.141, p.574601, 2015.

BARROWS, K.. Ideas in phychoanalysis envy. Londre: Cox \& Wyman Ltd. Reading, 2002.

BOARDMAN, D.; RACITI, M. M.; AWLEY, M.. Exploring the influence of envy on service engagement. The Service Industries Journal, v.36, n.7-8, p.278-298, 2016. DOI: http://doi.org/10.1080/02642069.2016.1186659

BUCZAK-STEC, E. W.; KÖNIG, H. H.; HAJEK, A.. Impact of incident parkinson's disease on satisfaction with life. Frontiers in Neurology, v.9, n.589, p.1- 4, 2018.

COHEN, S.; DOYLE, W. J.; TURNER, R. B.; ALPER, C. M.; SKONER, D. P.. Emotional style and susceptibility to the common cold. Psychosomatic Medicine, v.65, p.652-657, 2003.

COHEN-CHARASH, Y.. Episodic envy. Journal of Applied Social Psychology, v.39, p.2128-2173, 2009.

COHEN-CHARASH, Y.; MUELLER, J. S.. Does perceived unfairness exacerbate or mitigateinterpersonal counterproductive work behaviors related to envy?. Journal of Applied Psychology, v.92, p.666-680, 2007.

COOPER, D. R.; SCHINDLER, P. S.. Métodos de pesquisa em administração. 12 ed., Porto Alegre: AMGH, 2016.

CORICELLI, G.; RUSTICHINI, A.. Rustichini Counterfactual Thinking and Emotions: Regret and Envy Learning. Philosophical Transactions of The Royal Society B Biological Sciences, v.365, n.1538, p.241-247, 2009. DOI: http://doi.org/10.1098/rstb.2009.0159

COUTINHO, M. P. L.. Uso de técnicas projetivas na apreensão de representações sociais da sintomatologia da depressão infantil. Tese (Doutorado em psicologia) Universidade de São Paulo, São Paulo, 2001.

CRUSIUS, J.; LANGE, J.. How do people respond to threatened social status?. Moderators of benign versus malicious envy. In: SMITH, R. H.; MERLONE, U.; DUFFY, M. K. I Envy at Work and in Organizations: Research, Theory, and Applications. NewYork: Oxford University Press, 2017. p.85110.

CUKIER, R.. Psicossociodrama da inveja: atire a primeira pedra se você puder. Revista Brasileira Psicodrama, São Paulo, v.19, n.1, p.13-33, 2011.

DOGAN, K.; VECCHIO, R. P.. Managing employee envy in the workplace. Compensation and Benefits Review, v.33, n.2, p.57-64, 2001.

DUFFY, M. K.; GANSTER, D.; PAGON, M.. Social Undermining in the Workplace. Academy of Management Journal, v.45, p.331-351, 2002. DOI: http://doi.org.10.2307/3069350

DUFFY, M. K.; SCOTT, K. L.; SHAW, J. D.; TEPPER, B. J.; AQUINO, K.. A social context model of envy and social undermining. Academy of Management Journal, v.55, n.3, p.643-666, 2012.

DUFFY, M. K.; SHAW, J. D.; SCHAUBROECK, J.. Envy in organizational life. In: SMITH, R.. Envy: Theory and research. New York: Oxford University Press, 2008. p.167-189.

DUFFY, M. K.; SHAW, J. D.. The salieri syndrome consequences of envy in groups. Small Group Research, v.31, n.1, p.3-21, 2000.

FISKE, S. T. .Envy up, scorn down: How comparison divides us. American Psychologist, v.65, p.698-706, 2010.

GHANDI, M. Y.. Empirical examination of theoretical model of workplace envy: evidences from Jordan. Management Research Review, v.41, n.12, p.1438-1459, 2018.

GIL, A. C.. Métodos e técnicas de pesquisa social. São Paulo: Atlas, 2008.

GINO, F.; PERCE, L.. Dishonesty in the name of equity. Psychological Science, v.20, p.1153-1160, 2009.

GUIMELLI, C.. Le modèle des schèmes cognitifs de base: méthodes et applications. In: ABRIC, J. C.. Méthodes d'étude des représentations sociales. Ramonville Saint-Agne: Érès, 2003.

GREENBERG, J.; ASHTON-JAMES, C. E.; ASHKANASY, N. M.. Comparison of social processes in organizations.

Organizational Behavior and Human Decision Processes, v.102, p.22-41, 2007.

HARNOIS, G.; GABRIEL, P.. Mental Health and Work: Impact, Issues and Good Practice, Mental Health Policy and Service Development Department of Mental Health and Substance Dependence Non Communicable Diseases and Mental Health, Geneva, 2002.

HENNIGER, N. E.; HARRIS, C. R.. Envy across adulthood: the what and the who. Basic and Applied Social Psychology, v.37, p.303-318, 2015.

HUH, M. Y.; LEE, W. K.. The Relationship between Attachment Instability and Mental Health: Mediating Role of Dispositional Envy. International Journal of Emergency Mental Health and Human Resilience, v.20, n.1, p.1-6, 2018.

IGLESIAS, F.. Desengajamento moral. In: BANDURA, A.; AZZI, R. G.; POLYDORO, S.. Teoria social cognitiva: conceitos básicos. Porto Alegre: Artes Médicas, 2008. p.165-176.

KIM, S.; O'NEILL, J.W.; CHO, H.. When does an employee not help coworkers? The effect of leader-member exchange on employee envy and organizational citizenship behavior. International Journal of Hospitality Management, v.29, n.3, p.530-537, 2010.

KLEIN, M.. Envy and Gratitude and Other Works 1946-1963. London: The Hogarth Press and the Institute of PsychoAnalysis, 1975.

LANGE, J.; WEIDMAN A. C.; CRUSIUS, J.. The Painful Duality of Envy: Evidence for an Integrative Theory and a Meta- 
Analysis on the Relation of Envy and Schadenfreude. Journal of Personality and Social Psychology, v.114, n.4, p.572-598, 2018.

LANGE, J.; CRUSIUS, J.; HAGEMEYER, B.. The Evil Queen's dilemma: Linking narcissistic admiration and rivalry to benign and malicious envy. European Journal of Personality, v.30, p.168-188, 2016. Dol: http://doi:10.1002/per.2047

LANGE, J.; CRUSIUS, J.. The tango of two deadly sins: The social-functional relation of envy and pride. Journal of Personality and Social Psychology, v.109, p.453-472, 2015b. DOI: http://doi:10.1037/pspi0000026

MARIS, Z. D.; SAIDABADI, R. Y.; NIAZAZARI, K.. Introducing a model of Organizational envy management among university faculty members; a mixed research approach. International Review, v.3, n.4, p.25-39, 2016.

MEDEIROS, E. D.; SOARES, A. K. S.; NASCIMENTO, A. M.; SILVA, J. B. S.; GOUVEIA, V. V.. An ungrateful disposition: Psychometric properties of the Dispositional Envy Scale in Brazil. Paidéia (Ribeirão Preto). Advance online publication, 2016. DOI: http://doi:10.1590/1982-43272665201605

\section{MELO, S. C. A.. Bem-estar subjetivo e bem-estar no} trabalho: um estudo com idosos que trabalham. Dissertação (mestrado) - Universidade Federal de Uberlândia, Programa de Pós-Graduação em Psicologia, 2007.

MENON, T.; THOMPSON, L.. Envy at work. Harvard Business Review, v.88, n.4, p.74-79, 2010.

MERTEN, T. O.. Teste de Associação de Palavras na Psicologia e Psiquiatria: História, Método e Resultados. Revista Análise Psicológica, v.4, n.10, p.531-541, 1992.

MICELI, M.; CASTELFRANCHI, C.. The envious mind. Cognition and Emotion, v.21, n.3, p.449-479, 2007. DOI: http://doi.org/10.1080/02699930600814735

MILFONT, T. L.; GOUVEIA, V. V.. A capital sin: Dispositional envy and its relations to wellbeing. Revista Interamericana de Psicología, v.43, n.3, p.547-551, 2009.

MISHRA, P.. Green-eyed monsters in the workplace: antecedents and consequences of envy. Academy of Management Proceedings, v.2009, n.1, p.1-6, 2009.

NINIVAGGI, F. J.. Envy theory: perspectives on the psychology of envy. Maryland: Rowman \& Littlefield Publishers, Inc. Lanham, 2010.

O'NEILL, O. A.; MUELLER, J. S.. Demography, emotional expressivity, and undermining in a female-dominated organization. Academy of Management Proceedings, v.1, p.1-6, 2011

PETTIT, J. W.; KLINE, J. P.; GENCOZ, T.; GENCOZ, F.; JOINER, T. E.. Are happy people healthier? The specific role of positive affect in predicting self-reported health symptoms. Journal of Research in Personality, v.35, p.521-536, 2001.

PRESSMAN, S. D.; COHEN, S.. Does positive affect influence health?. Psychological Bulletin, v.131, p.925-971, 2005.

SAMPIERI, R. H.; COLLADO, C. F.; LUCIO, P. B.. Metodologia de pesquisa. 3 ed. São Paulo: McGraw-Hill, 2006.

SCHAUBROECK, J.; LAM, S. K.. Comparing lots before and after: Promotion rejectees'invidious reactions to promotees. Organizational Behavior and Human Decision Processes, v.94, p.33-47, 2004. DOI: http://doi.org/10.1016/j.obhdp.2004.01.001

SHAW, J. D.; DINEEN, B. R.; FANG, R.; VELLELLA, R. F.. Employee-organization exchange relationships, HRM practices, and quit rates of good and poor performers. Academy of Management Journal, v.52, n.5, p.1016-1033, 2009.

SIAS, P. M.; HEATH, R. G.; PERRY, T.; SILVA, D.; FIX, B.. Narratives of workplace friendship deterioration. Journal of Social and Personal Relationships, v.21, n.3, p.321-340, 2004.

SMITH, R. H.; KIM, S. H.. Comprehending Envy. Psychological Bulletin, v.133, n.1, p.46-64, 2007.

SMITH, R. H.; PARROTT, W. G.; DIENER, E.; HOYLE, R. H.; KIM, S. H.. Dispositional envy. Personality and Social Psychology Bulletin, v.25, p.1007-1020, 1999.

SMITH, R. H.; TURNER, T. J.; GARONZIK, R.; LEACH, C. W.; URCH-DRUSKAT, V.; WESTON, C. M.. Envy and schadenfreude. PSPB, v.22, n.2, p.158-168, 1996.

STEPTOE, A.; O'DONNELL, K.; MARMOT, M.; WARDLE, J. Positive affect and psychosocial processes related to health. British Journal of Psychology, v.99, p.211-227, 2008.

STERLING, C.; VAN DE VEN, N.; SMITH, R. H.. The two faces of envy: Studying benign and malicious envy in the workplace. In: SMITH, R. H.; MERLONE, U.; DUFFY, M. K.. Envy at Work and in Organizations: Research, Theory, and Applications. Oxford: Oxford University Press, 2016. p.57-84. DOI: http://doi.org/10.1093/acprof:oso/9780190228057.003.000 $\underline{3}$

TAI, K.; NARAYANAN, J.; MCALLISTER, D. J.. Envy as pain: rethinking the nature of envy and its implications for employees and organizations. Academy of Management Review, v.37, n.1, p.107-129, 2012.

TOMEI, P. A.. Inveja nas organizações. São Paulo: Makron Books, 1994.

THOMPSON, G.; GLASO, L.; MARTINSEN, O.. The relationships between envy and attitudinal and behavioral outcomes at work. Scandinavian Journal of Organizational Psychology, v.7, n.1, p.5-18, 2015.

VAN DE VEN, N.; ZEELENBERG, M.; PIETERS, R.. Leveling up and down: the experiences of benign and malicious envy. Emotion, v.9, n.3, p.419-429, 2009.

VAN DIJK, W. W.; OUWERKERK, J. W.; GOSLINGA, S.; NIEWEG, M.; GALLUCCI, M.. When people fall from grace: reconsidering the role of envy in schadenfreude. Emotion, v.6, n.1, p.156-160, 2006.

VECCHIO, R. P.. It's not easy being green: Jealousy and envy in the workplace. Research in Personnel and Human 
Resources Management, v.13, p.201-244, 1995.

VEIGA, J. F.; BALDRIDGE, D. C.; MARKO, A.; CZY, L.. Toward greater understanding of the pernicious effects of workplace. The International Journal of Human Resources Management, v.25, n.17, p.2364-2381, 2014.

VERDIANI, G. M. S.. Um estudo sobre a inveja no ambiente organizacional. Dissertação (Mestrado em Desenvolvimento Regional e Meio Ambiente) - Centro Universitário de Araraquara, Araraquara, 2006.

VERDUYN, P.; LEE, D. S.; PARK, J.; SHABLACK, H.; ORVELL, A.; BAYER, J.; YBARRA, O.. Passive Facebook usage undermines affective well-being: Experimental and longitudinal evidence. Journal of Experimental Psychology, General, v.144, p.480488, 2015. DOI: http://doi.org/10.1037/xge0000057

VIDAILLET, B.. Workplace envy. Palgrave Macmillan, 2008.

VRIES, M. F. R. K.. A inveja, grande esquecida dos fatores de motivação em gestão. In: CHANLAT, J.-F.. O Indivíduo na Organização: dimensões esquecidas. São Paulo: Atlas, 1996.

WACHELKE, J.; WOLTER, R.. Critérios de construção e relato da análise prototípica para representações sociais.

Psicologia: Teoria e Pesquisa, v.27 n.4, p.521-526, 2011.

A CBPC - Companhia Brasileira de Produção Científica (CNPJ: 11.221.422/0001-03) detém os direitos materiais desta publicação. Os direitos referem-se à publicação do trabalho em qualquer parte do mundo, incluindo os direitos às renovações, expansões e disseminações da contribuição, bem como outros direitos subsidiários. Todos os trabalhos publicados eletronicamente poderão posteriormente ser publicados em coletâneas impressas sob coordenação da Sustenere Publishing, da Companhia Brasileira de Produção Científica e seus parceiros autorizados. Os (as) autores (as) preservam os direitos autorais, mas não têm permissão para a publicação da contribuição em outro meio, impresso ou digital, em português ou em tradução. 